\title{
The characterization of microsporidian isolates (Nosematidae: Nosema) from five important lepidopteran pests in Taiwan
}

\author{
Shu-Jen Tsai, ${ }^{\mathrm{a}}$ Chu-Fang Lo, ${ }^{\mathrm{b}}$ Yamane Soichi, ${ }^{\mathrm{c}}$ and Chung-Hsiung Wang ${ }^{\mathrm{a}, *}$ \\ a Department of Entomology, National Taiwan University, Taipei 106, Taiwan \\ ${ }^{\mathrm{b}}$ Department of Zoology, National Taiwan University, Taipei 106, Taiwan \\ ${ }^{\mathrm{c}}$ Biological Laboratory, Faculty of Education, Ibaraki University, Mito 310-8512, Japan
}

Received 18 October 2002; accepted 21 January 2003

\begin{abstract}
Microsporidian isolates from five lepidopteran pests_Spodoptera litura, Spodoptera exigua, Helicoverpa armigera, Plutella xylostella, and Pieris spp.-were compared by spore morphology, infectivity to $S$. litura, Western-blot banding patterns, the sequences of small subunit rRNA gene (SSUrRNA sequence), and random amplified polymorphic DNA polymerase chain reaction (RAPDPCR). All the isolates could infect experimentally and multiply in the larvae of $S$. litura. The $S$. exigua isolate showed the highest virulence to the larvae of $S$. litura while the $P$. xylostella isolate showed the lowest. No significant differences either in spore morphology or in SSUrRNA sequences of these isolates were found. The SSUrRNA sequences of these isolates confirmed they are members of the genus Nosema. Based on the result of Western-blot hybridization with the rabbit anti-Nosema spodopterae spore antiserum, three serotypes could be distinguished: $N$. spodopterae ( $S$. litura isolate) and Pi. spp. isolate; S. exigua and H. armigera isolates; and P. xylostella isolate. The amplicons of RAPD-PCR with 60 primers yielded clear patterns that were selected and used for identification and also for phylogenic analysis of these five isolates. Based on analysis by the computer, isolates could be clearly divided into three groups that were coincident with the serotypes; therefore we suggest that $N$. spodopterae and isolates of $P i$. spp., $S$. exigua, and $H$. armigera are more closely related in phylogenesis. In addition, in the amplification with the Nosema bombycis specific primer set, only DNAs from $P$. xylostella isolate and $N$. bombycis yielded amplicons. Therefore, we suggest that four isolates, excluding the $P$. xylostella isolate, are $N$. spodopterae, and the taxonomic position of $P$. xylostella isolate needs to be elucidated. (C) 2003 Elsevier Science (USA). All rights reserved.
\end{abstract}

Keywords: Nosema spp.; Infectivity; RAPD; SSUrDNA; Western-blot hybridization

\section{Introduction}

Microsporidia have been usually considered primitive, without mitochondria, eukaryotic protists that are obligate intercellular parasites. They are very common in insects and in the intimate parasites of insect hosts, well adapted in pathogenicity, transmission, ecology, and resistance to the defense system of their hosts. Recently, molecular biological and genomic studies on microsporidia have concentrated on many unusual features, especially mitochondrial genes. The accumulation

\footnotetext{
${ }^{*}$ Corresponding author. Fax: +886-2-27364329.

E-mail address: wangch@ccms.ntu.edu.tw (C.-H. Wang).
}

of molecular evidence has shown that microsporidia are not really the most primitive eukaryotes, in fact, highly specialized fungi (Keeling and Fast, 2002). Insects in nearly all taxonomic orders are susceptible to this pathogen and over half of the susceptible insect hosts belong to one of two orders, Lepidoptera and Diptera. Several species of microsporidia play an important role in regulating insect populations (Tanada and Kaya, 1993). The members of genus Nosema are often considered the most important and widely distributed group of microsporidia.

The life cycle stages and parasite-host relations of microsporidia possess many unique ultrastructural characteristics and are critical to taxonomic determination 
of microsporidia genera and species. The taxonomy of microsporidia usually follows the system developed by Sprague (1977). Since many microsporidia are considered to have a wide host range (Tanada and Kaya, 1993), the life cycles and parasite-host relationships may be inadequate as taxonomic criteria in some cases, especially in species determination. In such cases, more reliable tools are needed for diagnosing and identifying intra- or interspecies. Protein and serologic analyses (Irby et al., 1986; Ke et al., 1990; Streett and Briggs, 1982) and the rRNA gene sequences (Baker et al., 1994; Malone and McIvor, 1996; Pieniazek et al., 1996; Visvesvara et al., 1994; Vossbrinck et al., 1987; Vossbrinck et al., 1993) of microsporidia have been commonly used for this purpose. In addition to rRNA gene sequencing, random amplified polymorphic DNA polymerase chain reaction (RAPD-PCR) has emerged as a fast and sensitive technique for distinguishing closely related organisms. This method had been used to assess the polymorphism of closely related microsporidian isolates of Encephalitozoon spp. obtained from different hosts (Mathis et al., 1996, 1997).

Microsporidian isolates from five important lepidopteran pests-the tobacco cutworm, Spodoptera litura; the beet armyworm, Spodoptera exigua; the corn earworm, Helicoverpa armigera; the diamondback moth, Plutella xylostella, and two cabbageworms, Pieris spp. (Pieris rapae crucivora and Pieris canidia sordida) -were collected in Taiwan. Considered the most economically devastating, these five lepidopterian pests have steadily increased their infestation of cruciferous vegetables in Taiwan and are frequently found even in the same crops. The microsporidian isolate of $S$. litura has been identified and named Nosema spodopterae (Hsu et al., 1992) while the taxonomic positions of other isolates are still unclear. It is reasonable to suspect that they may belong to the same species or closely related species. In an attempt to clarify their taxonomic position and understand their relationship, several characteristics-including morphology, infectivity to $S$. litura, protein, and Westernblot banding profiles-the sequences of small subunit rRNA (SSUrRNA) gene and RAPD-PCR of five isolates were examined and analyzed in this paper.

\section{Materials and methods}

\subsection{Microsporidian isolates and host culture}

Microsporidian isolates were collected from five lepidopteran pests: $S$. litura ( $N$. spodopterae abbreviated as SL); S. exigua (SE); H. armigera (HA); P. xylostella (PX); and Pieris spp. (PS). The spores of all isolates were harvested and propagated in the larvae of $S$. litura. The surrogate hosts were reared on an artificial diet (Koyama and Kamano, 1976) in a growth chamber at
$26 \pm 2{ }^{\circ} \mathrm{C}$ and $75-80 \%$ relative humidity. The photoperiodic regime was $12 \mathrm{~L} / 12 \mathrm{D}$. The surrogate hosts were inoculated with different concentrations $\left(1 \times 10^{3}, 1 \times\right.$ $10^{4}$, and $1 \times 10^{5}$ ) of each isolate's spores by a sporecontaminated artificial diet. Moribund larvae were collected and homogenized in Tris-EDTA buffer (TE; $10 \mathrm{mM}$ Tris, $1 \mathrm{mM}$ EDTA, $\mathrm{pH}$ 7.5). The homogenates were filtered through three layers of cheesecloth and centrifuged at $1000 \mathrm{~g}$ for $10 \mathrm{~min}$. The pellets were resuspended in TE buffer and the spores were purified by $90 \%$ Percoll (Pharmacia, Uppsala, Sweden) gradient centrifugation at 30,000g for $30 \mathrm{~min}$ (Tsai and Wang, 2001; T'sui et al., 1988). The spores formed a white band close to the bottom of the centrifugal tube. The spore band was collected and washed several times by TE buffer. The purified spores of type species, Nosema bombycis, were the gift of Dr. Sugimoto, MAFF GENE Bank of NIAS (National Institute of Agrobiological Science), Japan. They were stored at $4{ }^{\circ} \mathrm{C}$.

\subsection{Experimental infection to $S$. litura larvae}

Three doses, $1 \times 10^{3}, 1 \times 10^{4}$, and $1 \times 10^{5}$ spores, of each isolate and $N$. bombycis were dispensed onto the upper surface of an artificial diet $\left(5 \times 5 \mathrm{~mm}^{2}\right)$. Control insects were supplied with distilled water on an artificial diet only. Newly third instar larvae (5-day-old) of S. litura were starved in 30-well plastic plates for 4-6h before experimental infection. The larvae were then supplied or not supplied with a spore-contaminated artificial diet. Mortality of the larvae was recorded and calculated by probit analysis and the cadavers were collected and stored at $4{ }^{\circ} \mathrm{C}$. The spore yield of the infected larvae with each isolate at 30 days post-inoculation was also calculated. The spores were then purified by Percoll gradient centrifugation and stored at $4{ }^{\circ} \mathrm{C}$.

\subsection{Preparation of anti-N. spodopterae spore antiserum}

The anti- $N$. spodopterae spore antiserum was prepared in a male New Zealand White rabbit weighing about $1.5 \mathrm{~kg}$. One billion spores in $1 \mathrm{ml}$ phosphate buffered saline (PBS, pH 7.3) were shaken with $0.5 \mathrm{~g}$ glass beads $(0.5 \mathrm{~mm}$ diameter) to disrupt them (Tsai et al., 2002). The lysed spores were used as inoculum. The inoculum was emulsified with $0.5 \mathrm{ml}$ adjuvant. Freund's complete adjuvant was used for the first immunization and Freund's incomplete adjuvant for the following immunizations. After three boosts, the rabbit serum was used as antiserum for detection.

\subsection{SDS-polyacrylamide gel electrophoresis and Wes- tern-blot hybridization}

The spore-soluble polypeptides were prepared from the homogenates of $4 \times 10^{8}$ spores with glass beads, as 
described above. The homogenates were centrifuged at $15,000 \mathrm{~g}$ for $5 \mathrm{~min}$, and the supernatants were obtained by boiling them for $10 \mathrm{~min}$ in an equal volume of $2 \times$ SDS sample buffer $(10 \% \beta$-mercaptoenthanol, $4 \%$ SDS, and $0.01 \%$ bromophenol blue in $0.1 \mathrm{M}$ Tris- $\mathrm{HCl}$ buffer, $\mathrm{pH}$ 6.8). The polypeptides of the microsporidian isolates samples were separated by SDS-polyacrylamide gel electrophoresis (SDS-PAGE) with 12.5\% acrylamide gel (Laemmli, 1970). The polypeptide bands were transferred onto the nitrocellulose membranes by SEMIPHOR (Hoefer). The membranes were blocked with 3\% skim milk in Tris-buffered saline (TBS; $20 \mathrm{mM}$ Tris, $0.5 \mathrm{M} \mathrm{NaCl}, \mathrm{pH} 7.5$ ) for $1 \mathrm{~h}$, washed with TBS containing $0.05 \%$ Tween 20 (TTBS) for $3 \mathrm{~min}$, and then incubated with the rabbit anti-S. litura Nosema spore antiserum which were diluted 100 -fold for $1 \mathrm{~h}$. After triple washing with TTBS ( 3 min each), the membranes were incubated with a 1:2500 dilution of peroxidaseconjugated goat anti-rabbit IgG (Jackson ImmunoResearch Laboratories, West Grove, PA) for $1 \mathrm{~h}$. After three more washing with TTBS and one with TBS, the membranes were then incubated with a color-developing substrate solution. Hydrogen peroxide and 4-chloro1-naphthol were used as substrate and chromogen, respectively.

\subsection{Sequencing of small subunit $r R N A$}

Spore suspensions $\left(2 \times 10^{8}\right.$ spores in $0.25 \mathrm{ml}$ TE buffer) mixed with equal volumes of zirconia/silica beads $(0.1 \mathrm{~mm}$ diameter) in $10 \times 75 \mathrm{~mm}$ glass tubes were shaken at maximum speed on a vortex mixer for $1 \mathrm{~min}$ (modification of Undeen and Cockburn, 1989; Tsai et al., 2002). The homogenates were incubated with proteinase $\mathrm{K}$ for $1 \mathrm{~h}$ at $56^{\circ} \mathrm{C}$. DNA was extracted in phenol/chloroform, precipitated with ethanol, and then amplified by polymerase chain reaction (PCR). A primer set (18f/1537r: 5'-CACCA GGTTG ATTCT GCC-3'/5'TTATG ATCCT GCTAA TGGTT C-3') was used for amplification of the microsporidial SSUrRNA coding region (Vossbrinck et al., 1987, 1993). The DNA template $(100 \mathrm{ng})$ of each isolate was mixed in a $100 \mu \mathrm{le}$ action mixture containing $10 \mathrm{mM}$ Tris- $\mathrm{HCl}, \mathrm{pH} 9.0$, $50 \mathrm{mM} \mathrm{KCl}, 1.5 \mathrm{mM} \mathrm{MgCl}, 200 \mathrm{mM}$ of each dNTP, 100 pmol of each primer, and 2.5 U Taq DNA polymerase (Promega, Madison, WI). The amplification was performed in an AG-9600 Thermal Station (Biotronics Corp.) for 40 cycles, each with the following profile: $94^{\circ} \mathrm{C}$ for $1 \mathrm{~min}, 57^{\circ} \mathrm{C}$ for $1 \mathrm{~min}$, and $72^{\circ} \mathrm{C}$ for $2 \mathrm{~min}$. A $10 \mu \mathrm{l}$ aliquot from each reaction was run on a $1.0 \%$ agarose gel to visualize the PCR product. The DNA fragment of about $1.2 \mathrm{~kb}$ was then subcloned into the SmaI site of pUC18 vector, and both DNA strands of cloned DNA fragments were sequenced on an automated DNA sequencer (DNA sequencer 377, Applied Biosystems).

\subsection{Phylogenetic analysis}

The microsporidial SSUrRNA gene sequences of the isolates and the other lepidopteran host, from GenBank (Table 1) were aligned with the CLUSTAL X program (Thompson et al., 1997). The sequence from Vavraia oncoperae (Accession No. X74112) was an outgroup.

Table 1

The DNA sequences of microsporidia derived from lepidopteran hosts used for SSUrDNA phylogenetic analysis

\begin{tabular}{lll}
\hline Organism & Host & GenBank Accession No. \\
\hline Endoretuculatus schubergi & Lymantria dispar & $\mathrm{L} 39109$ \\
Nosema bombycis (SES-NU) & Bombyx mori & $\mathrm{D} 85503$ \\
Nosema furnacalis & Ostrinia furnacalis & $\mathrm{U} 26532$ \\
Nosema necatrix & Pseudaletia unipuncta & $\mathrm{U} 11051$ \\
Nosema portugal & Lymantria dispar & $\mathrm{AF} 033316$ \\
Nosema sp. (NIS-M11) & Bombyx mori & $\mathrm{D} 85501$ \\
Nosema bombycis (Sd-NU-IW8401) & Spodoptera depravata & $\mathrm{D} 85504$ \\
Nosema sp. HA & Helicoverpa armigera & $\mathrm{AF} 238240$ \\
Nosema sp. KU-9 & A noctuid moth & $\mathrm{AF} 141130$ \\
Nosema sp. SL & Spodoptera litura, S. exigua, & $\mathrm{AF} 238239$ \\
& Plutella xylostella, and Pieris spp. & \\
Nosema trichoplusiae & Trichoplusia ni & $\mathrm{U} 09282$ \\
Nosema tyriae & Tyria jacobaeae & $\mathrm{AJ} 012606$ \\
Pleistophora sp. (ATCC 50040) & Agrotis exclamationis & $\mathrm{U} 10342$ \\
Pleistophora sp. (Sd-NU-IW8201) & Spodoptera depravata & $\mathrm{D} 85500$ \\
Vairimorpha imperfecta & Plutella xylostella & $\mathrm{AJ} 131645$ \\
Vairimorpha lymantriae & Lymantria dispar & $\mathrm{AF} 033315$ \\
Vairimorpha lymantriae (2) & Lymantria dispar & AF141129 \\
Vairimorpha necatrix & Malacosma americanum & Y00266 \\
Vairimorpha sp. & Lymantria dispar & $\mathrm{L} 39114$ \\
Vairimorpha sp. (Germany) & Plutella xylostella & AF124331 \\
Vairimorpha sp. (NIS-M12) & Bombyx mori & $\mathrm{D} 85502$ \\
Vavraia oncoperae & Wiseana sp. & X74112 \\
\hline
\end{tabular}


Phylogenetic analysis based on the resultant alignment was using neighbor-joining algorithm methods for distance analysis (Kimura 2-parameter) with PAUP 4.0b8 (Swofford, 1998). One-thousand bootstrap replicates and one-hundred characters resampling were generated to test the robustness of the tree.

\subsection{Random amplified polymorphic DNA}

RAPD-PCR amplifications were performed according to the standard technique described by Williams et al. (1990) with minor modifications. A total of 100 primers of five Operon 20-primer sets-OPA, OPAC, OPBD, OPO, and OPU (Operon Technologies, Alameda, CA) - were used as RAPD primers. The total volume of the reaction mixture was $25 \mu \mathrm{l}$, containing $10 \mathrm{ng}$ DNA, $50 \mathrm{mM} \mathrm{KCl}, 10 \mathrm{mM}$ Tris- $\mathrm{Cl}(\mathrm{pH} 9.0$ at $25^{\circ} \mathrm{C}$ ), $0.1 \%$ Triton $\mathrm{X}-100,2.0 \mathrm{mM} \mathrm{MgCl} 2,0.2 \mathrm{mM}$ each $\mathrm{dNTP}, 0.2 \mu \mathrm{M}$ primer, and $0.625 \mathrm{U}$ Taq DNA polymerase. The samples were incubated in $0.2 \mathrm{ml}$ tubes in an AG-9600 Thermal Station for $2 \mathrm{~min}$ at $94{ }^{\circ} \mathrm{C}$ (the initial denaturation step) and then for 45 cycles consisting of $94^{\circ} \mathrm{C}$ for $1 \mathrm{~min}, 36^{\circ} \mathrm{C}$ for $1 \mathrm{~min}$, and $72^{\circ} \mathrm{C}$ for $2 \mathrm{~min}$. Following these cycles the samples were incubated at $72{ }^{\circ} \mathrm{C}$ for $7 \mathrm{~min}$ and then held at $4{ }^{\circ} \mathrm{C}$. RAPD polymorphism was analyzed on $1.6 \%$ ethidium bromidestained agarose gels and photographed using the EagleEye II photo-documentation system (Stratagene). Sixty of 100 primers were able to yield clear amplicon bands, and these were used for analysis. Selected amplicons were number-coded and scored as present or absent for each isolate. The number of shared bands was used for the similarity measure and the consistently amplified DNA fragments were used to produce a pairwise matrix using the Jaccard similarity coefficients. The coefficients were employed to construct dendrograms based on the Unweighted Pair-Group Method with Arithmetic Averages (UPGMA) applying software from the NTSYSpc v. 2.01b (Rohlf, 1997).

\subsection{Specific primers $P C R$}

The KAI01N (5'-GTA GTA GAG ACC CAA CTA TC-3') and KAI02N (5'-ACT GTT CAG ATA TGG
TCC TTA TCG- $3^{\prime}$ ) primers were modified from a sequence of a putative pseudogene of small subunit $N$. bombycis SES-NU rRNA (Kawakami et al., 1995). The PCR conditions were described above and the amplicon patterns were photographed using the Eagle-Eye II photo-documentation system (Stratagene).

\section{Results}

\subsection{Morphology and pathogenicity of the isolates}

Spore sizes of the five isolates were $4.00 \pm 0.17 \times$ $1.90 \pm 0.12 \mu \mathrm{m}(\mathrm{SL}), 3.98 \pm 0.25 \times 1.90 \pm 0.12 \mu \mathrm{m}(\mathrm{SE})$, $4.03 \pm 0.26 \times 1.89 \pm 0.14 \mu \mathrm{m}(\mathrm{HA}), 3.96 \pm 0.21 \times 1.88 \pm$ $0.10 \mu \mathrm{m}(\mathrm{PX})$, and $4.01 \pm 0.21 \times 1.88 \pm 0.11 \mu \mathrm{m}$ (PS), respectively. No significant difference among these isolates was indicated by Duncan's multiple range test.

The third instar larvae of $S$. litura are susceptible to all microsporidian isolates. The median lethal doses $\left(\mathrm{LD}_{50}\right)$ of the five isolates to third instar larvae of S. litura were $1.78 \times 10^{3}(\mathrm{SL}), 1.10 \times 10^{3}(\mathrm{SE}), 4.28 \times$ $10^{3}(\mathrm{HA}), 2.88 \times 10^{3}(\mathrm{PX})$, and $1.29 \times 10^{3}(\mathrm{PS})$ spores/ larva at 30 days post-inoculation, respectively (Table 2 ). The cumulative mortality of the larvae is shown in Fig. 1. Apparently, SE isolate showed the highest virulence to the larvae of $S$. litura (formed an S-shaped curve), and PX isolate showed the lowest. Except SE isolate, the high spore yields of the infected $S$. litura larvae were obtained at a high dosage of $1 \times 10^{5}$ (Table 2). Therefore, the larvae of $S$. litura were to be a substitute for these five isolates in this study.

\subsection{Western-blot banding patterns}

The result of Western-blot hybridization with rabbit anti $N$. spodopterae spore antiserum is shown in Fig. 2. The major bands were found at ranges from 72 to $49 \mathrm{kDa}, 44$, and $26 \mathrm{kDa}$. Based on the banding patterns, three serotypes, SL/PS, SE/HA, and PX could be distinguished. The patterns of SL/PS type (lanes 1 and 5) contained six bands: $72,60,54,50,44$, and $26 \mathrm{kDa}$ (Fig. 2, lanes 1 and 5). In addition to the six bands of SL/PS type, $67 \mathrm{kDa}$, was found in SE/HA type (Fig. 2, lanes 2

Table 2

Infectivity of five isolates to the third instar larvae of $S$. litura at 30 days post-inoculation

\begin{tabular}{llllr}
\hline Nosema isolates $^{\mathrm{a}}$ & $\begin{array}{l}\mathrm{LD}_{50} \text { at the 30th day } \\
\text { (spores/larva) }\end{array}$ & $\begin{array}{l}\mathrm{LT}_{50} \\
(\text { days })^{\mathrm{b}}\end{array}$ & $\begin{array}{l}\text { Spores yield } \\
\text { (spores/larva) }^{\mathrm{b}}\end{array}$ & $\begin{array}{l}\text { Mortality rate } \\
(\%)^{\mathrm{b}}\end{array}$ \\
\hline SL & $1.78 \times 10^{3}$ & 14.81 & $7.16 \times 10^{8}$ & 98.88 \\
SE & $1.10 \times 10^{3}$ & 10.82 & $4.09 \times 10^{7}$ & 100.00 \\
HA & $4.28 \times 10^{3}$ & 18.93 & $1.17 \times 10^{9}$ & 91.01 \\
PX & $2.88 \times 10^{3}$ & 22.01 & $2.49 \times 10^{9}$ & 93.26 \\
PS & $1.29 \times 10^{3}$ & 16.35 & $1.78 \times 10^{8}$ & 95.56 \\
\hline
\end{tabular}

${ }^{a}$ Abbreviations of isolates from $S$. litura (SL), S. exigua (SE), H. armigera (HA), P. xylostella (PX), and Pieris spp. (PS, including Pi. rapae crucivora and Pi. canidia sordida).

${ }^{\mathrm{b}}$ At dosage $1 \times 10^{5}$ spores/larva. 


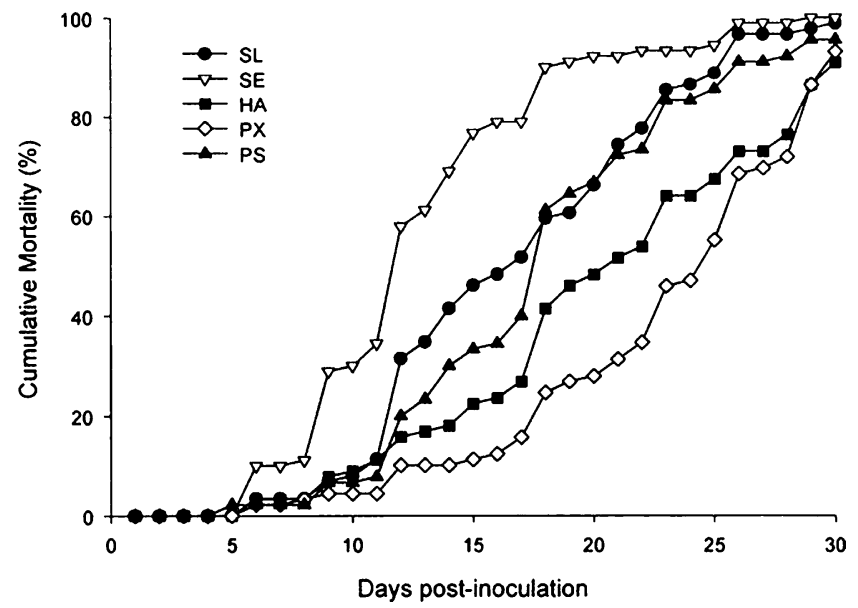

Fig. 1. The cumulative mortality $(\%)$ of the third instar larvae of Spodoptera litura infected with microsporidian isolates $\left(1 \times 10^{5}\right.$ spores). Abbreviations of the isolates are SL, SE, HA, PX, and PS derived from S. litura, S. exigua, H. armigera, P. xylostella, and Pieris spp. (including Pi. rapae crucivora and Pi. canidia sordida) respectively.

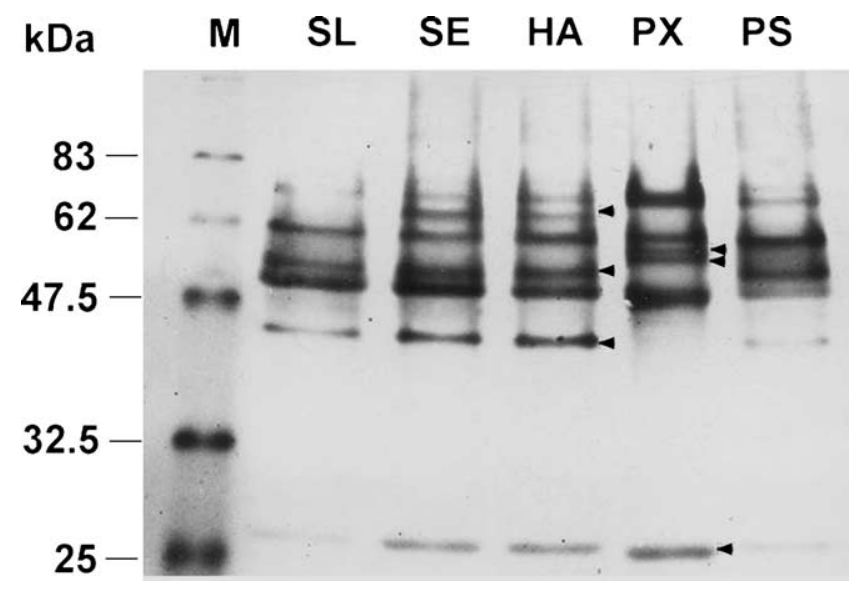

Fig. 2. Western-blot hybridization of the spore-soluble polypeptides of five isolates with rabbit anti-Nosema spodopterae spore antiserum. Three serotypes can be distinguished: SL/PS (lanes 1 and 5), SE/HA (lanes 2 and 3), and PX (lane 4). Abbreviations of the isolates are SL, SE, HA, PX and PS derived from S. litura, S. exigua, H. armigera, $P$. xylostella, and Pieris spp. (including Pi. rapae crucivora and Pi. canidia sordida), respectively. Molecular weights are given in $\mathrm{kDa}$ on the left. Arrowheads show the unique bands of isolates.

and 3). PX type showed a most different pattern that contained two unique bands at 58 and $56 \mathrm{kDa}$ (Fig. 2, lane 4) and lacked three bands: 67, 54, and $44 \mathrm{kDa}$.

\subsection{SSUrDNA sequences}

The amplified SSUrRNA gene region length of each isolate is $1232 \mathrm{bp}$. The sequences of four isolates (SL, SE, PX, and PS) are identical and only one base is different from HA isolate at position 821 from the $5^{\prime}$-end of the SSUrRNA gene. Both sequences were submitted to the GenBank, and the accession numbers were AF238239 (SL series) and AF238240 (HA). Phyloge- netic analysis suggests that the microsporidia from lepidopteran can be divided into three distinct groups: the Nosema, Vairimorpha, and Endoreticulatus groups. The sequence of SSUrRNA gene of Vavraia oncoperae was used as an outgroup for this analysis (Fig. 3). The Nosema group consists of $N$. bombycis complex and $\mathrm{No}$ sema furnacalis. The members of $N$. bombycis complex are the type species of genus Nosema, $N$. bombycis, most of the Nosema species, and two Vairimorpha species from $P$. xylostella. The Vairimorpha group consists of two subgroups, Vairimorpha necatrix complex, including the type species of genus Vairimorpha, V. necatrix, and Vairimorpha lymantriae complex, most members of which are derived from gypsy moth, Lymantria dispar, except for Nosema sp. KU-9, derived from a noctuid moth. Nosema sp. NIS-M11 is another Nosema species in Vairimorpha group, but it was considered a Vairimorpha species (Iguchi et al., 1997). The Endoreticulatus group consists of Endoreticulatus schubergi and two Pleistophora species from noctuid moths.

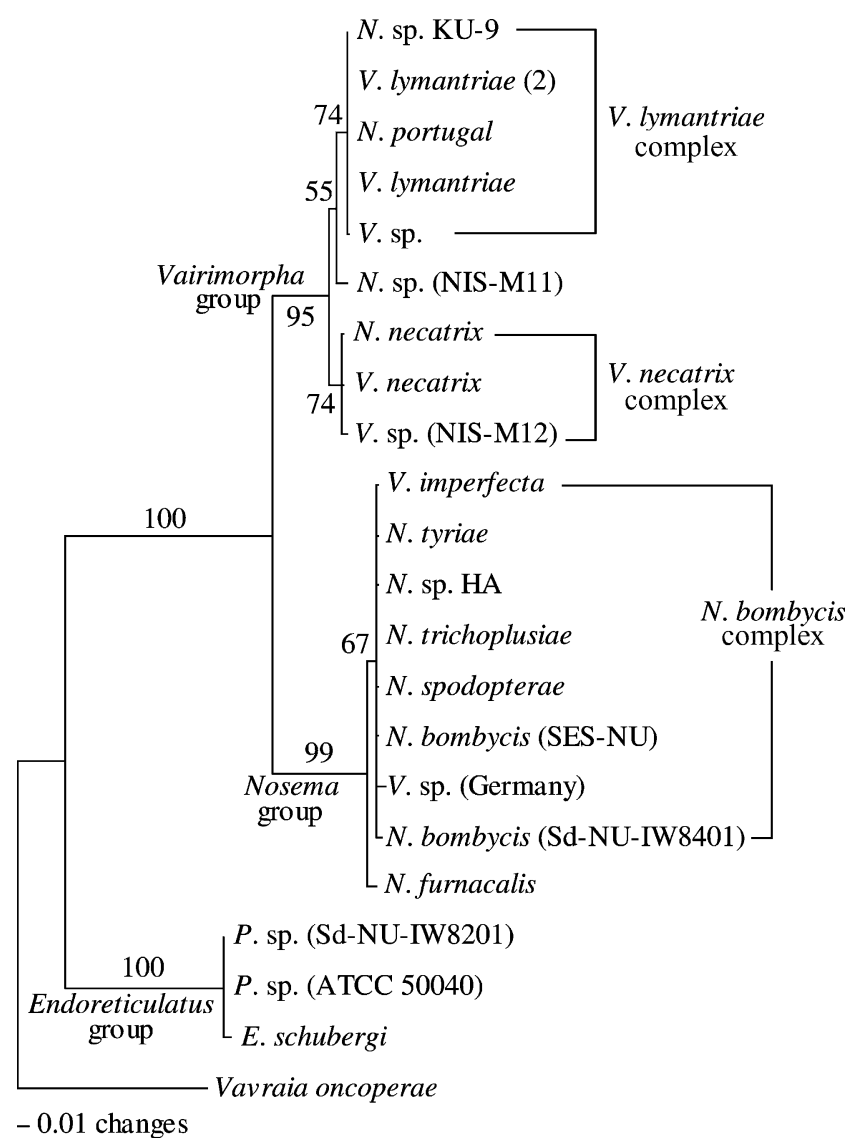

Fig. 3. Phylogenetic relationships among microsporidia divided from lepidopteran hosts based on SSUrDNA sequences. The tree was generated by the neighbor-joining method using Kimura two-parameter distances. The Vavraia oncoperae was used as an outgroup. Numbers next to the nodes refer to the bootstrap scores (\%) in 1000 replicates. E, Endoreticulatus; N, Nosema; P, Pleistophora; V, Vairimorpha. 


\subsection{RAPD analysis}

The efficiency of primers to generate a clear amplicon pattern after RAPD-PCR with isolate DNA was evaluated, and 60 primers were chosen and used for this study. Fig. 4 shows the representation of the amplicon patterns. Three distinct patterns could be distinguished. Based this, the primers were conveniently divided into: (1) nondiscrimination (8 primers): OPAC- $01,-15,-19$; OPO-03, -20 (Fig. 4A); and OPU-09, -10, -13; (2) discrimination among five microsporidia (3 primers): OPAC-09; OPO-10; and OPU-16 (Fig. 4B); and (3) partial discrimination consists of two subgroups: (I) three types (NS/PS, SE/HA, and PX, similar to serotypes; 11 primers): OPA-05, -08, -14, -15, -16; OPBD-11, $-17,-18,-20$ (Fig. 4C); and OPU-01, -17; (II) two types (PX and others not included in the second and third (I) groups; 38 primers): OPA-03, -04, -06, -07, -09, -12, -13, $-17,-18$; OPAC-03, $-05,-07,-10,-12,-13,-14,-17,-18$; OPBD-04, -05, -06, -07, -12, -14, -15; OPO-06, -13, -14; and OPU-02, -03 (Fig. 4D), -06,-08, -12, -14, -15, -18, $19,-20$. In the phylogenetic analysis, the five isolates were clearly divided into three groups (Fig. 5): SL/PS,
(A)

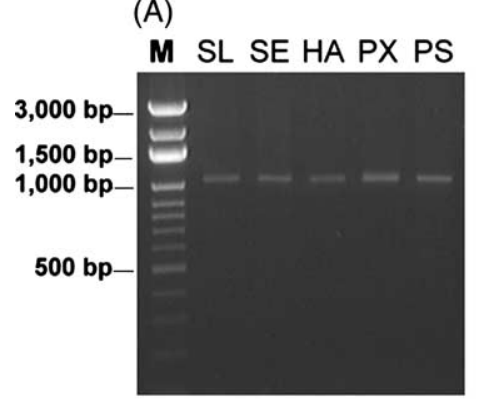

(C)

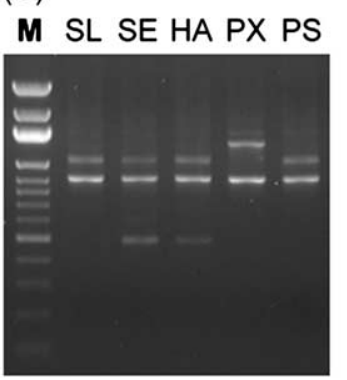

(B)

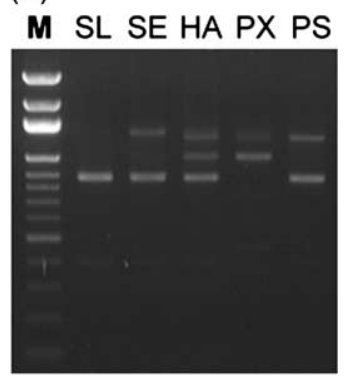

(D)

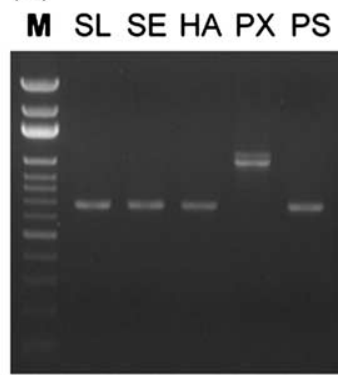

Fig. 4. Four distinct amplicon patterns (A-D) of RAPD-PCR profiles for five microsporidian isolates with primer sets (OPA, OPAC, OPBD, OPO, and OPU) could be distinguished. The representative RAPDPCR profiles for each pattern are shown: (A) nondiscrimination: the profile of OPU-20; (B) discrimination: five types: the profile of OPU16; (C) partial discrimination: (I) three types (NS/PS, SE/HA, and PX): the profile of OPBD-20; and (D) partial discrimination: (II) two types (PX and others that are not including in $\mathrm{B}$ and $\mathrm{C}$ ): the profile of OPU03. M: Bio100 DNA ladder marker. Abbreviations of the isolates are SL, SE, HA, PX, and PS derived from S. litura, S. exigua, H. armigera, $P$. xylostella, and Pieris spp. (including Pi. rapae crucivora and $P i$. canidia sordida), respectively.

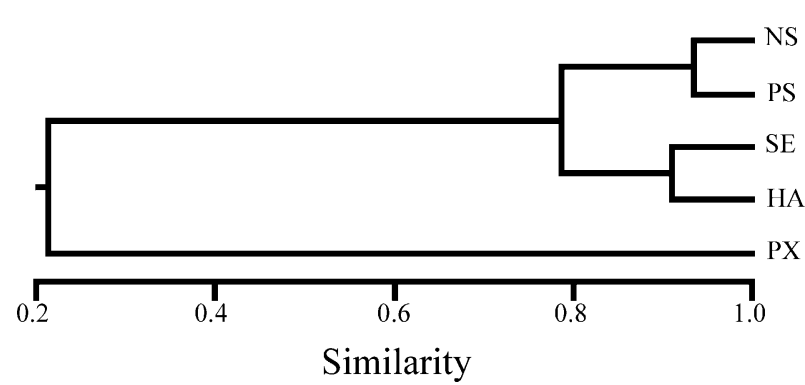

Fig. 5. UPGMA dendrogram built from Jaccard's genetic distance matrix based on 248 RAPD fragments. Abbreviations of the isolates are SL, SE, HA, PX, and PS derived from S. litura, S. exigua, $H$. armigera, $P$. xylostella, and Pieris spp. (including $P$. rapae crucivora and $P i$. canidia sordida), respectively.

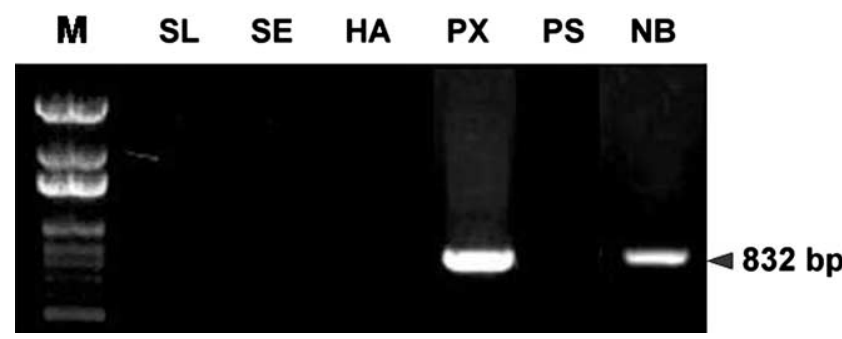

Fig. 6. Agarose gel electrophoresis pattern of PCR amplification products of five microsporidian isolates by KAI01N/KAI02N primerset showing that only PX (lane 4) and $N$. bombycis (lane 6) yield amplicons with $832 \mathrm{bp}$. Abbreviations of the isolates are SL, SE, HA, PX, PS, and BM derived from $S$. litura, S. exigua, H. armigera, P. xylostella, Pieris spp. (including Pi. rapae crucivora and Pi. canidia sordida), and B. mori, respectively. M: Bio100 DNA.

SE/HA, and PX. The isolates of SL and PS clustered with more than $93.5 \%$ similarity. The isolates of SE and HA clustered with more than $91 \%$ similarity. The similarity between SE/HA and SL/PS groups was $78.8 \%$. PX isolate clustered with other isolates with about $21.3 \%$.

\subsection{Specific primers $P C R$}

Fig. 6 shows KAI01N/KAI02N primer set produced an amplicon of PCR only with the DNA from spores of PX isolate and N. bombycis, but the others did not. Both amplicons are $832 \mathrm{bp}$ (GenBank Accession No. AF310844). The sequences of both amplicons have only one base difference at position 48 (C) from the $5^{\prime}$-end, " $\mathrm{T}$ " in the $N$. bombycis pseudogene of $N$. bombycis SESNUrRNA (GenBank Accession No. D14632) and "C" in that of PX isolate.

\section{Discussion}

Many reports have described the microsporidia from lepidopteran hosts. Okada (1970) has been recorded the microsporidian from $S$. litura in Japan, and Watanabe (1976) first described the Nosema species of S. litura. 
This Nosema species did not have any harmful effects on the silkworm, Bombyx mori, even at high dosages for inoculation. Ke et al. (1990) indicated that $N$. liturae (Nosema species derived from S. litura) shared a common antigen determinant and were apparently closely related to other Nosema species from lepidopteran hosts. S. exigua was found infected by Nosema isolate, Nosema sp. Y9101, and this isolate was considered a strain of $N$. bombycis based on morphology and serology (Yasunaga et al., 1992). In Taiwan, the isolate from the larvae of $S$. litura was described and named $N$. spodopterae (Hsu et al., 1991, 1992). The massive microsporidian infections of the larvae of these lepidopteran pests, $S$. litura, $S$. exigua, $H$. armigera, $P$. xylostella, and $P i$. spp., occur in different seasons. The massive infections of $S$. litura, $S$. exigua, and $H$. armigera larvae occur in the fall, and those of $P$. xylostella and Pi. spp. larvae occur in the later spring and early summer in Taiwan. The microsporidian spores collected from these pests are morphologically similar, and they can infect experimentally and be multiplied in the surrogate host, the larvae of $S$. litura, while they are not susceptible to $N$. bombycis spores. In addition, the high similarity in the SSUrRNA sequences of five isolates implied that they are closely related in phylogeny and may even be the same species. In phylogenetic analysis, the SSUrRNA sequences of five isolates were aligned with other known micrsosporidan SSUrRNA gene sequences of species that infect the lepidopteran hosts (Fig. 3). The result leads us to confirm that these isolates are members of the $N$. bombycis complex and belong to the genus Nosema.

Both SSU and LSUrRNA genes are highly conserved among species while ITS is highly variable rRNA with a high rate of evolution. Canning et al. (1999) considered this highly conserved gene (SSUrRNA) useless in distinguishing between very closely related species, even those that can be distinguished on morphological criteria. Indeed, the SSUrRNA framework in each group is similar, but it can work on determination of an unknown species in high taxon and yet not work on identification of a closely related species (Fig. 3). We have found the sequences containing internal transcribed space (ITS) and partial of the $5^{\prime}$-end large subunit rDNA (LSUrDNA) from the Vairimorpha group (Accession Nos. AF141129, AF141130, AF033315, AF033316, and V. necatrix in Vossbrinck et al., 1993) but not from the Nosema group. Although a partial LSUrRNA gene sequence (Accession No. L28962) of $N$. bombycis (Baker et al., 1994) had been published, we could not find any ITS sequences of the Nosema group in the literature. Furthermore, only four microsporidian complete rRNA gene sequences-Encephalitozoon cuniculi (Peyretaillade et al., 1998), Microsporidium 57864 (GenBank Accession No. U90885), Nosema apis (De Rijk et al., 1998), and Heterosporis anguillarum (Tsai et al., 2002)-have been published. It implied that a vast difference of rRNA gene exists in the course of a high reduction of their genome and gene structure during evolution. Therefore, efforts to complete the rRNA gene sequences, especially in Nosema spp., will be a great contribution to understanding interspecies phylogenetic relationships. Among the isolates we collected, there were no significant difference in SSUrRNA sequences, but we believed that PX isolate was a distinct species. So far, we have carried out the complete sequence of $N$. spodopterae rRNA gene sequences (AY211390AY211392), but those of other isolates, especially PX isolate and type species, $N$. bombycis, are also necessary to carry out what will be a great help in the Nosema species clarification.

Morphological characters and life cycle are the major criteria used to identify the microsporidia, but the species between genera Nosema and Vairmorpha are still ambiguous. In the phylogenetic analysis based on the SSUrRNA sequences (Fig. 3), several diversions, compared the identification in morphology, occur. The members of $N$. bombycis complex are very closely related, and they include two Vairimorpha species from $P$. xylostella. Canning et al. (1999) indicated that Vairimorpha imperfecta and the German isolate of Vairimorpha from the host $P$. xylostella were more closely related to the Nosema species from lepidoptera than to the Vairimorpha species. They chose to name it Vairimorpha because of the morphological characters. In addition, these two Vairimorpha species did not form octospores or sporophorous vesicles. This evidence hints at the need for a possible reexamination of the taxonomic position of these two species.

A similar situation appears in the Vairimorpha subgroup. The $V$. lymantriae complex consists of two $\mathrm{No}$ sema species, Nosema portugal and Nosema sp. KU-9. Besides the Nosema KU-9, the others were all derived from gypsy moths, Lymantria dispar. $N$. portugal had been observed to have uninucleate meronts in merogonic cycles (Maddox et al., 1999), but it was not a characteristic typical of genus Nosema. $V$. necatrix complex contains $N$. necatrix too. The Pleistophora species from lepidopteran hosts are closely related to Endoreticulatus schubergi. Baker et al. (1995) suggested the Pleistophora sp. ATCC50040 (Accession No. U10342) was an Endoreticlulatus species. These two Pleistophora species are not closely related to those that infect aquatic organisms.

The results of Western blot hybridization (Fig. 2) and Cluster analysis of RAPD (Fig. 4) characters showed that five Nosema isolates could be separated into three phenetic groups. In comparing RAPD profiles of the isolates, PX isolate shared only $21.3 \%$ of bands with others, indicating it was really genetically distinct from other isolates. Thus, it corroborated the results of Western blot hybridization. Furthermore, this conclusion was also confirmed by PCR with $N$. bombycis 
specific primer set (KAI01N/KAI02N) (Kawakami et al., 1995). Only DNA from PX isolate and N. bombycis yielded amplicons (Fig. 6), and the amplicon sequences were identical, except for one nucleotide. Undoubtedly, PX isolate is a member of the genus Nosema but not of $N$. spodopterae. Indeed, the taxonomic position of $P$. xylostella isolate needs to be clarified in further study, especially the evidence of ultrastructure and other molecular markers.

\section{Acknowledgments}

This investigation was supported by the National Science Council (Grant No. NSC-91-2313-B-002-360), ROC. We thank Dr. S.S. Kao of the Taiwan Agricultural Chemicals and Toxic Substances Research Institute for collection of the infected insects; and Dr. R. Sugimoto of the MAFF GENE Bank of the National Institute of Agrobiological Science, Japan for giving the type species, $N$. bombycis. We also acknowledge Dr. S.F. Shiao for his assistance in the PAUP and NTSYS-pc analyses.

\section{References}

Baker, M.D., Vossbrinck, C.R., Maddox, J.V., Undeen, A.H., 1994. Phylogenetic relationships among Vairimorpha and Nosema species (Microspora) based on ribosomal RNA sequence data. J. Invertebr. Pathol. 64, 100-106.

Baker, M.D., Vossbrinck, C.R., Didier, E.S., Maddox, J.V., Shadduck, J.A., 1995. Small subunit ribosomal DNA phylogeny of various microsporidia with emphasis on AIDS related forms. J. Eukaryot. Microbiol. 42, 564-570.

Canning, E.U., Curry, A., Cheney, S., Lafranchi-Tristem, N.J., Haque, M.A., 1999. Vairimorpha imperfecta $\mathrm{n}$. sp., a microsporidian exhibiting an abortive octosporous sporogony in Plutella xylostella L. (Lepidoptera: Yponomeutidae). Parasitology 119, 273-286.

De Rijk, P., Gatehouse, H.S., de Wachter, R., 1998. The secondary structure of Nosema apis large subunit ribosomal RNA. Biochim. Biophys. Acta 1442, 326-328.

Hsu, T.H., Hsu, E.L., Yen, F.Y., 1991. Spore ultrastructure of a microsporidian species (Nosema sp.) from the tobacco cutworm, Spodoptera litura. Chinese J. Entomol. 11, 242-251 (in Chinese with English summary).

Hsu, T.H., Hsu, E.L., Yen, D.F., 1992. Nosema spodopterae n. sp., a new species of microsporidia from the tobacco cutworm, Spodoptera litura. J. Agric. Assoc. (China) 157, 81-90 (in Chinese with English summary).

Iguchi, T., Iwano, H., Hatakeyama, Y., Kawakami, Y., Onoda, K., Hayasaka, S., Inoue, T., Ishihara, R., 1997. Sporogony of a microsporidium, Nosema sp. NIS-M11 (Microspora: Nosematidae) in larvae of the silkworm, Bombyx mori raised under two distinct level of temperature. J. Seric. Sci. Jpn. 66, 445-452 (in Japanese with English summary).

Irby, W.S., Huang, Y.S., Kawanishi, C.Y., Brooks, W.M., 1986. Immunoblot analysis of exospore polypeptides from some entomophilic microsporidia. J. Protozool. 33, 14-20.

Kawakami, Y., Inoue, T., Uchida, Y., Hatakeyame, Y., Iwano, H., Ishihara, R., 1995. Specific amplification of DNA from reference strains of Nosema bombycis. J. Seric. Sci. Jpn. 64, 165-172 (in Japanese with English summary).

Ke, Z., Xie, W., Wang, X., Long, Q., Pu, Z., 1990. A monoclonal antibody to Nosema bombycis and its use for identification of microsporidian spores. J. Invertebr. Pathol. 56, 395-400.

Keeling, P.J., Fast, N.M., 2002. Microspoeidia: biology and evolution of highly reduced intracellular parasites. Annu. Rev. Microbiol. 56, 93-116.

Koyama, H., Kamano, S., 1976. Mass production of tobacco cutworm, Spodoptera litura. Plant Protect. 30, 470-474 (in Japanese).

Laemmli, U.K., 1970. Cleavage of structural proteins during the assembly of the head of bacteriophage T4. Nature 227, 680-685.

Maddox, J.V., Baker, M.D., Jeffords, M.R., Kuras, M., Linde, A., Solter, L.F., McManus, M.L., Vavra, J., Vossbrinck, C.R., 1999. Nosema portugal, n. sp., isolated from gypsy moths (Lymantria dispar L.) collected in Portugal. J. Invertebr. Pathol. 73, 1-14.

Malone, L.A., McIvor, C.A., 1996. Use of nucleotide sequence data to identify a microsporidian pathogen of Pieris rapae (Lepidoptera, Pieridae). J. Invertebr. Pathol. 68, 231-238.

Mathis, A., Akerstedt, J., Tharaldsen, J., Odegaard, O., Deplazes, P., 1996. Isolates of Encephalitozoon cuniculi from farmed blue foxes (Alopex lagopus) from Norway differ from isolates from Swiss domestic rabbits (Oryctolagus cuniculus). Parasitol. Res. 82, 727730.

Mathis, A., Michel, M., Kuster, H., Muller, C., Weber, R., Deplazes, P., 1997. Two Encephalitozoon cuniculi strains of human origin are infectious to rabbits. Parasitology 114, 29-35.

Okada, M., 1970. The control of grass pest insects by entomogenous microorganisms. Agric. Horticult. 45, 677-682 (in Japanese).

Peyretaillade, E., Biderre, C., Peyret, P., Duffieux, F., Metenier, G., Gouy, M., Michot, B., Vivares, C.P., 1998. Microsporidian Encephalitozoon cuniculi, a unicellular eukaryote with an unusual chromosomal dispersion of ribosomal genes and a LSU rRNA reduced to the universal core. Nucleic Acids Res. 26, 35133520.

Pieniazek, N.J., da Silva, A.J., Slemenda, S.B., Visvesvara, G.S., Kurtti, T.J., Yasunaga, C., 1996. Nosema trichoplusiae is a synonym of Nosema bombycis based on the sequence of the small subunit ribosomal RNA coding region. J. Invertebr. Pathol. 67, 316-317.

Rohlf, R.J., 1997. NTSYS-pc v. 2.01b Numerical Taxonomy and Multivariate Analysis System. Applied Biostatistics Inc, Setauket, NY.

Sprague, V., 1977. Classification and phylogeny of the microsporidia. In: Bulla Jr., L.A., Cheng, T.C. (Eds.), Comparative Pathobiology. Systematics of the Microsporidia, vol. 2. Plenum Press, New York, pp. $1-30$.

Streett, D.A., Briggs, J.D., 1982. An evaluation of sodium dodecyl sulfate-polyacrylamide gel electrophoresis for the identification of microsporidia. J. Invertebr. Pathol. 40, 159-165.

Swofford, D.L., 1998. PAUP*, Phylogenetic Analysis Using Parsimony (* and other methods), Version 4.0b4a. Sinaur Associates, Sunderland, MA.

Tsai, S.J., Kou, H.H., Lo, C.F., Wang, C.H., 2002. Complete sequence and structure of ribosomal RNA gene of Heterosporis anguillarum. Dis. Aquat. Org. 49, 199-206.

Tsai, S.J., Wang, C.H., 2001. Interaction of the microsporidium and nucleopolyhedrovirus in Spodoptera litura. Formosan Entomol. 21, 183-195 (in Chinese with English abstract).

T'sui, W.H., Wang, C.H., Lo, C.F., 1988. On the Pleistophora infection in eel. II. The development of Pleistophora anguillarum in experimental infected elvers, Anguilla japonica. Bull. Inst. Zool. Acad. Sinica 27, 249-258.

Tanada, Y., Kaya, H.K., 1993. Protozoan infections: Apicomplexa, Microspora. In: Insect Pathology. Academic Press, San Diego, pp. $414-458$ 
Thompson, J.D., Gibson, T.J., Plewniak, F., Jeanmougin, F., Higgins, D.G., 1997. The CLUSTAL X windows interface: flexible strategies for multiple sequence alignment aided by quality analysis tools. Nucleic Acids Res. 25, 4876-4882.

Undeen, A.H., Cockburn, A.F., 1989. The extraction of DNA from microsporidia spores. J. Invertebr. Pathol. 54, 132-133.

Visvesvara, G.S., Leitch, G.J., da Silva, A.J., Croppo, G.P., Moura, H., Wallace, S., Slemenda, S.B., Schwartz, D.A., Moss, D., Bryan, R.T., Pieniazek, N.J., 1994. Polyclonal and monoclonal antibody and PCR-amplified small-subunit rRNA identification of a microsporidian, Encephalitozoon hellem, isolated from an AIDS patient with disseminated infection. J. Clin. Microbiol. 32, 2760-2768.

Vossbrinck, C.R., Baker, M.D., Didier, E.S., Debrunner-Vossbrinck, B.A., Shadduck, J.A., 1993. Ribosomal DNA sequences of Encephalitozoon hellem and Encephalitozoon cuniculi: species identification and phylogenetic construction. J. Eukaryot. Micorbiol. $40,354-362$.
Vossbrinck, C.R., Maddox, J.V., Frideman, S., Debrunner-Vossbrinck, B.A., Woese, C.R., 1987. Ribosomal RNA sequence suggests microsporidia are extremely ancient eukaryotes. Nature 326, 411414

Watanabe, H., 1976. A Nosema species of the Egyptian cotton leafworm, Spodoptera litura (Lepidoptera): its morphology, development, host range, and taxonomy. J. Invertebr. Pathol. 28, 321328.

Williams, J.G.K., Kubelik, A.R., Livak, K.J., Rafalski, J.A., Tingey, S.V., 1990. DNA polymorphisms amplified by arbitrary primers are useful as genetic markers. Nucleic Acids Res. 18, 65316535.

Yasunaga, C., Funakoshi, M., Kawarabata, T., Aratake, Y., Iwano, H., 1992. Isolation and characterization of Nosema bombycis (Microsporida: Nosematidae) from larvae of beet armyworm, Spodoptera exigua. Jpn. J. Appl. Entomol. Zool. 36, 127-134 (in Japanese with English summary). 